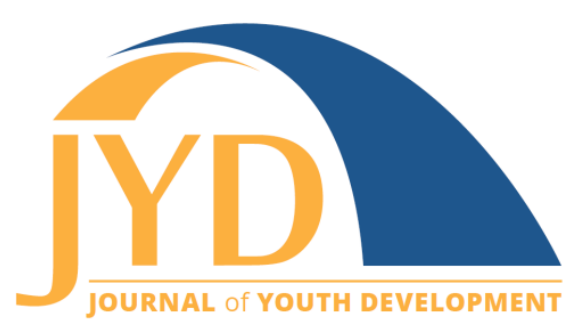

http://jyd. pitt. edu/ | Vol. 14 Issue 2 DOI 10.5195/jyd.2019.692 | ISSN 2325-4017 (online)

\title{
Examining Resiliency in Adolescent Refugees Through the Tree of Life Activity
}

\author{
Marcella D. Stark \\ Texas Christian University, College of Education \\ m.stark@tcu.edu

\section{Brandy P. Quinn} \\ Texas Christian University, College of Education \\ b.quinn@tcu.edu
}

\section{Katharine A. Hennessey}

Texas Christian University, College of Education

k.ottone@tcu.edu

\section{Amanda A. Rutledge}

Texas Christian University, College of Education arutledge@nchstx.org

\section{Allison K. Hunter}

Texas Christian University, College of Education a.k.hunter@tcu.edu

\section{Paola K. Gordillo}

Texas Christian University, College of Education gordillo.kp@gmail.com

\section{Abstract}

Grounded in both resiliency science and positive youth development, the research team set out to understand the strengths and resources of adolescent refugees living in northeast Texas. In coordination with a local refugee services agency, members of the research team conducted the Tree of Life activity with 16 participants ranging in age from 13 to 20 years. Identifying 16 codes in the qualitative analyses of participants'drawings, they organized these codes into 3 themes: self-efficacy, values, and relationships. The authors recommend the use of Tree of Life and other creative arts activities to

(cc) EY New articles in this journal are licensed under a Creative Commons Attribution 4.0 License. This journal is published by the University Library System, University of Pittsburgh and is cosponsored by the University of Pittsburgh Press. The Journal of Youth Development is the official peer-reviewed publication of the National Association of Extension 4-H Agents and the National AfterSchool Association. 
Examining Resiliency Through Tree of Life

facilitate the discovery of strengths and resources in adolescent refugees, by which they may progress beyond survival of adversity to resiliency and thriving.

Key words: resiliency, developmental assets, Tree of Life, adolescent, refugees

Refugees are individuals who have been forced to leave their home countries because of persecution, war, or other violence, and who are fearful of persecution "for reasons of race, religion, nationality, political opinion, or membership in a particular social group" ("What is a refugee," n.d., para. 1). By definition, then, refugees have faced trauma and likely need various types of support to move through and beyond circumstances of extreme challenge to well-being and thriving. There are 22.5 million individuals classified as refugees by the United Nations Refugee Agency, and about half of these individuals are under the age of 18 ("Figures at a glance," n.d.). In the current study, the authors investigated a particular way to leverage the Tree of Life drawing activity to learn about the strengths and resources that adolescent refugees identify in themselves.

The authors grounded this study in two related, yet distinct, strands of scholarship: resilience and positive youth development (PYD). Resilience has been contemporarily defined as "the capacity of a dynamic system to adapt successfully to disturbances that threaten system function, viability or development" (Masten, 2014a, p. 6). PYD researchers share a commitment to understanding the necessary conditions for positive adaptation, with a special focus on adolescents and their capacity to thrive. Thriving is an optimal developmental state in which the individual moves beyond wellbeing to become someone who is able to contribute in positive ways to multiple levels of the system, beginning with taking care of the self, and spiraling out to broader contributions to family, community, and society (Lerner, Dowling, \& Anderson, 2003; Masten, 2014b). With a systems approach in mind, the authors of the present study brought together the focus on overcoming adversity (from resiliency science) with the adolescent focus and potential for thriving (from PYD research) to better understand the ways in which adolescent refugees may already identify strengths and resources in themselves.

\section{Background}

\section{Migrant Experience}

The adolescent refugees in the study are classified as Unaccompanied Refugee Minors (URM). Although researchers agree that URM are a very vulnerable group, prone to more psychiatric morbidity than other adolescent groups, it is difficult to obtain a clear understanding of their migrant experience because data collection is limited and varies between countries (Huemer et 
Examining Resiliency Through Tree of Life

al., 2009). That said, Bean, Derluyn, Eurelings-Bontekoe, Broekaert, and Spinhoven (2007) noted that URM in the Netherlands have a higher number of stressful, if not traumatic, life events than other youth there. They noted that it is not clear whether the increased risk for psychopathology comes from these life events or from the lack of parental care (or both, considering that stressful life events often result from a lack of adult supervision). Keles, Friborg, Idsöe, Sirin, and Oppedal (2018) published similar findings, noting that $79 \%$ of the URM in Norway had experienced war, and "URMs all have experienced loss of or separation from family members" (p. 53). Despite these challenges, Keles et al. noted that $60 \%$ of their URM participants were considered to be healthy or resilient.

In her study of URM who migrate from Mexican and Central American countries to the United States, Franco (2018) explained the migration experience as "a tripartite process consisting of: pre-migration exposure to traumatic stressors, in-journey stressors, and post-migration stressors" (p. 551). Franco shared similar findings to European researchers, except that her participants' pre-migration traumatic experiences often involved violence unrelated to war. The journey to the United States is unique to this population and typically involves the use of human smugglers known as coyotes or transport via La Bestia (i.e., a cargo train; Dominquez Villegas, 2014). Along this journey, URM are exposed to potential abuse, as well as malnourishment and dehydration (Franco, 2018). When they arrive in the United States, URM from countries that do not border the United States are protected from deportation without a court hearing. However, the detention centers where they wait are often overcrowded; have limited access to food, water, restrooms, and medical care; and in some cases, expose URM to abuse by staff members of the detention center (Collier, 2015). After this initial stay, URM are placed with family members, sponsors, or foster care-with varying levels of care and provision of basic needs-where they must make adult decisions of pursuing work or education (Franco, 2018).

\section{Characteristics of Adolescence}

Regardless of their country of origin, adolescent refugees share many of the challenges that all refugees face. Their education falters during the time they live in refugee camps, and a language barrier often keeps refugees on the outskirts of society, unable to fully integrate and experience their own familiar culture beyond their temporary homes (Capps et al., 2015; Tshabangu-Soko \& Caron, 2011). However, particular characteristics of adolescence, specified as ages 12 to 21 by the American Academy of Pediatrics (2017), are salient for thinking about how individuals during this stage may identify and use their strengths as they navigate their experiences of being refugees. First, adolescence marks a significant time in the lifelong process 


\section{Examining Resiliency Through Tree of Life}

of identity construction (Kroger, Martinussen, \& Marcia, 2010). Second, adolescents, as compared to younger children, possess more complex cognitive abilities to understand and describe the self, and they undergo a process of integrating many aspects of the self into one (Harter, 1990; Sebastian, Burnett, \& Blakemore, 2008). Finally, adolescents have stronger social cognitive skills than younger children (e.g., perspective-taking), but these skills are not yet at adult levels of competency (Blakemore \& Mills, 2014). Taken together, these characteristics mean that adolescent refugees may be particularly well-suited to reflect on their own strengths and resources, and, with support, to move towards positive adaptation.

In addition, PYD researchers have shown that adolescence is a period of time during which the presence of internal and external assets is influential in moving individuals towards thriving (Scales, Benson, \& Leffert, 2000). The developmental assets framework includes 40 assets which "reflect broad conceptualizations about strength-based, positive child and youth development that are explicated in the key developmental socialization processes of connection, support, regulation, autonomy, and competencies" (Sesma, Mannes, \& Scales, 2005, p. 282). The assets include 20 external assets, such as family support, other adult relationships, the availability of creative activities, and religious communities, and 20 internal assets, such as school engagement, achievement motivation, values like caring and honesty, the ability to plan and make decisions, and a positive view of one's personal future (Sesma et al., 2005). From a PYD perspective, then, adolescent refugees who use their growing self-awareness skills to recognize their internal assets, especially when supported by practitioners and communities who ensure the presence of more external assets, may move beyond positive adaptation and to thriving.

Similar to models of resilience, the developmental assets framework represents a classification system for factors that encourage healthy adaptation and for positive developmental outcomes that are present with or without adversity (Sesma, et al., 2005). Resilience researchers have described developmental cascades in the same cumulative manner in which developmental assets are envisioned as both factors that contribute to positive outcomes and the positive outcomes themselves (Masten \& Cicchetti, 2010). Specifically, protective or promotive factors of resilience influence outcomes that themselves become new protective or promotive factors.

\section{Resiliency Research}

Henderson and Millstein (2003) discuss how resiliency research has progressed from identifying factors that harm people to identifying how people bounce back from tough circumstances and 


\section{Examining Resiliency Through Tree of Life}

emerge with even more strengths and resources than before. They noted that resiliency research has come in three waves (resilient qualities, process of resilience, innate resilience) throughout the past few decades. Early researchers investigated individual risk factors and protective factors. This wave of research focused on finding correlations between people who were already experiencing significant problems and their previous life experiences, which researchers then categorized as risk factors. Risk factors include personality characteristics, family system, gender, age, epigenetics, and genetics. This first wave of research also emphasized protective factors, which act as buffers to stressful events and help individuals maintain or return to their original homeostasis (Henderson \& Millstein, 2003). Protective factors include individual traits, family influence, and community support (Werner, 2005). In the second wave, researchers focused on the process of growth, having moved from assessing risk factors, individual traits, and protective factors, to focusing on how individuals create meaning, develop coping skills, and engage creativity and spirituality (Greene, 2010; Henderson \& Millstein, 2003). Focusing on resiliency instead of risks is a choice that researchers and practitioners make, seeing clients as "survivors not casualties" (Werner, 2005, p.11).

A key implication for interventions based upon this second wave of resilience research is that they look towards developing assets and resources and not back on vulnerabilities (Fergus \& Zimmerman, 2005). Practitioners who utilize interventions to increase resiliency still honor and validate the difficult life circumstances of their clients without the focus being on the individual's risk factors. Furthermore, practitioners who work with adolescents can focus on their unique strengths and needs, with a goal of positively influencing their clients' natural journey towards more resiliency.

\section{Profile of a Resilient Adolescent}

A profile of a resilient adolescent grounds the present study. The researchers cautiously offer this profile because it could be misinterpreted as a list of traits needed to be resilient, a prescription for raising a child, or a sentence to a life without resilience. Instead, in this profile, resiliency is understood as a dynamic, natural process that is different for every person. Rutter (2012) recommends that, when discussing resiliency, the terms mechanism or process are used and not factor. Therefore, the profile includes mechanisms and developmentally appropriate processes of resiliency that could be present in an adolescent. Having such a profile helped the research team to identify, highlight, and amplify possible resiliency mechanisms in adolescent refugees. 
Examining Resiliency Through Tree of Life

Henderson and Millstein (2003) reviewed resiliency literature to provide a list of internal characteristics and environmental factors that facilitate resiliency in adolescents. Their list included internal characteristics, such as social skills and a focus on relationships, confidence, goal-oriented behavior, self-sufficiency, and a positive outlook, and environmental factors, such as a positive relationship with an adult, warmth, personal safety, encouragement, opportunities to contribute to the community, and support of education and personal interests (see Henderson \& Millstein, 2003, p. 9 for full listing). One goal of the present study was to provide practitioners with a range of possible strengths that may be present in their adolescent refugee clients. If adolescents can identify these characteristics within themselves, they may be empowered to discover qualities in themselves they can either strengthen or develop (Henderson \& Millstein, 2003). These aspects of resiliency are certainly not exhaustive, but they provided the research team a starting point for identifying characteristics of resiliency in this study's population.

\section{Tree of Life Activity}

The Tree of Life (TOL) activity was initially created for community counselors working in southern Africa with vulnerable children, orphaned or otherwise impacted by HIV/AIDS (Ncube, 2006). The counselors noticed that the traditional methods of therapy were exhausting the clients' resources and a novel approach was desperately required. In 2005, a team from the Dulwich Centre Foundation, an Australian organization that develops, practices, and teaches narrative therapy (Dulwich Centre, n.d.), visited the Masiye Camp in Zimbabwe to explore how best to work with these children (Ncube, 2006). The Tree of Life metaphor was initially introduced by educators Ann Hope and Sally Timmel in their "Training for Transformation: A Handbook for Community Workers" (1984 as cited in Denborough, 2008). A tree must inhabit many strengths to withstand the storms and intense weather patterns that occur. In collaboration with David Denborough of the Dulwich Centre Foundation, Ncazelo Ncube (2006) took this idea and developed an exercise around this metaphor. The metaphor was useful in designing the Tree of Life exercise with this population and provided a foundation of identifying shelter and strength that would help the children to share their traumatic experiences in a manner that protected and reinforced their resources. Because this process does not require verbalization of traumatic memories, children who are not ready to discuss their history can still benefit from the process. As a result, this approach has been used with children who have experienced trauma and loss in a myriad of settings (Denborough, 2008; Hughes, 2013; Mendez \& Cole, 2014; Ncube, 2006). 


\section{Examining Resiliency Through Tree of Life}

The TOL activity is a valuable tool for refugee adolescents to identify their strengths and existent coping skills. In this activity, facilitators first invite a discussion about what members know about trees and their parts (i.e., roots, trunk, branches, leaves, fruit, and seeds). They also explain how compost heaps are used to produce fertilizer. The facilitator then asks participants to draw a tree, using words and pictures in various parts of the tree to represent aspects of their lives. Recognizing that participants may recall aspects that have been an influence, but which they do not wish to be defining, facilitators instruct participants to put these aspects in their compost heap. The roots describe where participants come from (e.g., culture, language, country of origin), and the ground represents the participants' lives in the present (e.g., where they live now, how they spend their time). The trunk portrays special skills; the leaves include important people (past or present, real or imaginary); and the fruit represents gifts (i.e., kindness and lessons) that have been given to them. Participants may also draw seeds left from the fruit to symbolize how they wish to impact the world. When all the drawings are complete, participants put their trees together to make a forest, and each participant writes words of encouragement or admiration on the other drawings. The facilitator concludes the activity by talking about how trees weather storms, encouraging participants to consider how they may be resilient in weathering the storms of life.

Mendez and Cole (2014) concluded that the TOL activity facilitates a dialogue about families' cultural values, beliefs, resources, strengths, and supports and is especially helpful in getting adolescents who are reluctant to share to open up because it allows their expression of feeling and experience. Furthermore, Ncube (2006) proposed that the TOL activity gives participants a sense of hope for the future by appreciating their skills and competencies. Using this approach, adolescents identify parts of their unique experiences to impact their resilience and to reach their goals. In Hughes' (2013) study, participants viewed the TOL activity as an educational project that reinforced their identity and transformed some aspects of their lives.

The TOL activity is one example of how creative arts may be used in populations for whom a linguistic barrier is present. Davis (2010) discussed how artwork facilitates the organization of thinking and the expression of emotions for those who find it difficult to express themselves in English. Similarly, Hughes (2013) noted that language barriers make it "more difficult to develop trusting therapeutic relationships. Even where interpreters are used, this requires additional skills on the part of practitioners to make this effective" (p. 141). She found that the use of imagery in the TOL activity is helpful when verbal communication is limited. 


\section{Examining Resiliency Through Tree of Life}

To sum, the model of developmental assets and the resiliency literature, particularly Henderson and Millstein's (2003) characteristics, provided the theoretical framework for the present study. The TOL activity was the creative mechanism by which the study's participants self-identified these characteristics. In tandem, the two frameworks provided the research team with a method for discovering strengths and resources of one group of adolescent refugees.

\section{Method}

In effort to understand resiliency in adolescent refugees living in northeast Texas, the researchers led participants in the TOL activity as a tool to narrate their experiences and to identify existent coping strategies. The primary research question was "What are strengths and resources of adolescent refugees in northeast Texas?" Collective case studies involve the study of more than one instrumental case (Stake, 2005), allowing researchers to analyze specific aspects of a group. The researchers selected this methodology to explore self-perceptions of strengths in a group of adolescent refugees. Having a shared belief that each individual constructs his or her own reality within a social context, the research team adopted a social constructionist paradigm (Berger \& Luckmann, 2007). Both collective case study methodology and social constructionist theory shaped the methodology of this study.

\section{Participants}

After obtaining approval through a university Institutional Review Board, the research team sought assistance from a counselor with a local charitable organization who works with refugees to learn more about the population and to recruit participants. The researchers used a purposive criterion sampling procedure (Patton, 2014) with the following criteria: (a) be a refugee between the ages of 13 to 21 years, (b) reside in northeast Texas, and (c) have classification as an "unaccompanied refugee minor" with the aforementioned charitable organization. After explaining the purpose and procedures for the study in English and Spanish, the researchers obtained informed consent and assent from both participants and the organization's counselor who had guardian rights.

A total of 16 participants ranged in age from 13 to 20 years. Fourteen of the youth came to Texas with a refugee designation, and the other two initially identified as state unaccompanied migrant children but received Special Immigrant Juvenile Status and were later reclassified as URMs. The participants came from six different countries and spoke seven different languages (in addition to more recent learning of English); their time in the United States ranged from 10 
months to 6 years. Specific data are available in Table 1. Three participants resided in agencyrun foster homes, and the others were living in individual foster homes throughout the community.

Table 1. Participant Demographics

\begin{tabular}{|c|c|c|}
\hline & Frequency & Percent \\
\hline \multicolumn{3}{|l|}{ Gender } \\
\hline Female & 5 & $31.25 \%$ \\
\hline Male & 11 & $68.75 \%$ \\
\hline \multicolumn{3}{|c|}{ Country of Origin } \\
\hline Burma & 5 & $31.25 \%$ \\
\hline Congo & 1 & $6.25 \%$ \\
\hline Eritrea & 7 & $43.75 \%$ \\
\hline El Salvador & 1 & $6.25 \%$ \\
\hline Honduras & 1 & $6.25 \%$ \\
\hline Iraq & 1 & $6.25 \%$ \\
\hline \multicolumn{3}{|c|}{ First Language } \\
\hline Arabic & 1 & $6.25 \%$ \\
\hline Karen & 1 & $6.26 \%$ \\
\hline Rohingya & 3 & $18.75 \%$ \\
\hline Spanish & 2 & $12.50 \%$ \\
\hline Swahili & 1 & $6.25 \%$ \\
\hline Thai & 1 & $06.25 \%$ \\
\hline Tigringya & 7 & $43.75 \%$ \\
\hline \multicolumn{3}{|c|}{ Length of time in U.S. } \\
\hline 10 months & 1 & $6.25 \%$ \\
\hline 1 year & 3 & $18.75 \%$ \\
\hline 2 years & 10 & $62.50 \%$ \\
\hline 3 years & 1 & $6.25 \%$ \\
\hline 6 years & 1 & $6.25 \%$ \\
\hline
\end{tabular}

\section{Research Team and Procedure}

The research team consisted of six females from the same university: two faculty members (one from educational psychology and one from counseling), two doctoral counseling students, 


\section{Examining Resiliency Through Tree of Life}

and two master-level counseling students. Concurrently, the researchers led Ncube and Denborough's narrative TOL activity (Ncube, 2006) in three groups of five to six participants. The two doctoral students each guided a group through the TOL activity in English; in the third group, which included two Spanish-speaking participants who needed additional language support, the TOL activity was facilitated in both English and Spanish by one of the master-level students.

The researchers assigned numbers to participants to protect their confidentiality. In each group, one researcher facilitated the activity while another researcher observed, wrote field notes, and digitally photographed the completed drawings. All members of the team participated in coding and analyzing the data.

\section{Data Analysis}

The TOL drawings served as artifacts, which may be considered a type of concept map overlaid on the metaphor of a tree. Concept maps "focus on the meaning associated with visual representations of experience, knowledge, perception, or memory" and can be defined as "graphical tool[s] for organizing and representing knowledge" (Wheeldon, 2010, p. 90). In this case, the TOL artifacts represented participants' knowledge about themselves. The research team reviewed these artifacts using a process of open coding (i.e., noting themes that emerged in the concept maps) and then developed refined codes, useful for identifying categories and patterns in the data (Miles, Huberman, \& Saladaña, 2013). The team based these refined codes on Henderson and Millstein's (2003) characteristics of resiliency, as the process of open coding revealed alignment between the data and Henderson and Millstein's framework. However, the research team further modified some codes to better fit the participants' wording. For example, Henderson and Millstein's positive view of the future characteristic became future orientation to reflect the diverse affect of participants' future-oriented statements.

The research team sought consensus at each stage of analysis. Specifically, research team members wrote descriptions of drawings from groups other than those they facilitated or observed. Next, a member of the research team who had not been involved in data collection reviewed each drawing and written description, and she subsequently created an Excel spreadsheet which included key words/text for each drawing based on a part of the tree (e.g., trunk, leaves, fruit). Adding table cells of color observations, spatial observations, and other observations, the other four student researchers then reviewed each drawing and description and added their perceptions to the table. The resulting spreadsheet of keywords and text 
Examining Resiliency Through Tree of Life

served as a written transcript, which the entire research team reviewed and upon which they conducted axial and selective coding (Strauss \& Corbin, 1990). The research team conducted multiple rounds of analysis, in which each researcher color-coded and recoded the text, discussing any points of disagreement until they reached consensus. The researchers then imported the data into ATLAS.ti (Muhr, 2009), a qualitative data analysis software program, and used a process of classical content analysis (Leech \& Onwuegbuzie, 2007), counting the number of times each code appeared in the data to determine salient and significant themes: self-efficacy, values, and relationships. In some cases, participant responses received more than one code. For instance, the researchers coded "love and preach to the world" as both cooperation and altruism (a value) and future orientation (characteristic of self-efficacy).

\section{Trustworthiness}

Due to limited access to the participants and language barriers, checking with participants about the interpretations of the research team was not possible. However, the research team met multiple times to discuss interpretations of the data and reach consensus. Additionally, they kept an audit trail and code manual during the data collection and analysis process and provided a detailed account of their methodological selections. To support the credibility for this study, a case worker who regularly works with the adolescent refugee population validated the researchers' interpretations. Finally, the researchers compared their interpretations of the data with findings of previous researchers.

\section{Findings}

The research team identified 16 codes in the qualitative analyses of participants' drawings, and they organized these codes into three themes: (a) self-efficacy, (b) values, and (c) relationships. See Table 2 for the themes, frequency, and an example quotation of each code. Participants saw themselves as strong, competent, and hard-working, and these strengths provided self-efficacy, or a belief that participants can achieve their goals. Participant values, such as religion and education, constituted a second area of strength. Finally, the most frequently noted resources for participants were their relationships with others. 
Journal of Youth Development ｜ http://jyd.pitt.edu/ | Vol. 14 Issue 2 DOI 10.5195/jyd.2019.692

Examining Resiliency Through Tree of Life

\section{Table 2. Themes, Coding Frequency, and Example Quotations}

\begin{tabular}{|c|c|c|}
\hline $\begin{array}{l}\text { Themes and individual } \\
\text { codes }\end{array}$ & Frequency & Example quotations \\
\hline Self-efficacy & 86 & \\
\hline $\begin{array}{l}\text { Assertive, impulse control, and } \\
\text { good decision making }\end{array}$ & 9 & my job ethics; patient \\
\hline Competence & 2 & $\begin{array}{l}\text { one thing am good at is to play soccer; a coach asked me to join } \\
\text { his team }\end{array}$ \\
\hline Future orientation & 43 & $\begin{array}{l}\text { I believe that I wil get my reward in some day; to not do that is } \\
\text { going impact in the future }\end{array}$ \\
\hline Self-confidence & 4 & I'm good; confident \\
\hline Unique talents & 28 & $\begin{array}{l}\text { good at soccer and at cooking; soccer/football/basketball; like } \\
\text { choir sing in church and school }\end{array}$ \\
\hline Values & 67 & \\
\hline Altruism and cooperation & 16 & $\begin{array}{l}\text { keep your heart open for everyone; I went to cochg wold is to } \\
\text { sotp people to do bad things; I can help people; make my } \\
\text { Generacian better }\end{array}$ \\
\hline Autonomy/independence & 4 & $\begin{array}{l}\text { I have learned to rely on myself because everyone else has other } \\
\text { things to do; we were self taught because no one taugh as how } \\
\text { to play; able to help myself }\end{array}$ \\
\hline Education valued and promoted & 33 & $\begin{array}{l}\text { study well in school; homework; go to college or university; get } \\
\text { degrees }\end{array}$ \\
\hline Religion & 5 & I like going church; Islam; Evangelical \\
\hline Hard work & 9 & $\begin{array}{l}\text { I got this idea from my heart; I just think about my past and I } \\
\text { want to make it better, so I had the idea to improve my life }\end{array}$ \\
\hline Relationships & 169 & \\
\hline $\begin{array}{l}\text { At least one close relationship } \\
\text { with an adult }\end{array}$ & 13 & $\begin{array}{l}\text { my case manager; [refugee service agency] is important } \\
\text { (workers); my teachers }\end{array}$ \\
\hline Basic needs met & 19 & food, clothing; money; house; health \\
\hline Family & 72 & $\begin{array}{l}\text { I love family together; my mother and sisters are the important } \\
\text { people in my life; foster parents }\end{array}$ \\
\hline $\begin{array}{l}\text { Friendly/Has positive } \\
\text { relationships }\end{array}$ & 29 & $\begin{array}{l}\text { I really love to play with friends; I want to be the one person } \\
\text { anyone can rely on \& come to; my Pats }\end{array}$ \\
\hline Emotional support & 36 & halp me breve; love; iencorage; helpful; rember in your heart \\
\hline
\end{tabular}




\section{Self-Efficacy}

Self-efficacy refers to individuals' beliefs that they can accomplish their goals (Bandura, 1977). The participants showed several traits of self-efficacy, including the following: future orientation; competence; self-confidence; unique talents, and assertiveness, impulse control, and good decision making. Of these five strengthening aspects, the most common participant responses (43 instances) involved a future orientation. Having a future orientation included statements about dreams related to their desired professions, family goals, and qualities of self. Some participants used a future-focus regarding returning to their home countries and making future generations safer. The second most frequently-used code (28 instances) entailed participants' own unique talents. Half of these recordings mentioned exercise or sports, with soccer being the most commonly noted. The last three self-efficacy categories of assertiveness, impulse control, and good decision making (nine instances); competence (two instances); and self-confidence (four instances) may also play a role in resilience, but the other two categories (future orientation and unique talents) seem to occur more frequently in participant responses.

\section{Values}

Values, as described by Remley and Herlihy (2016), both help individuals to define good behavior and influence behavior choices; some values are more important than others in the personal system. In their TOL drawings, the participants included several values which impacted their experiences and abilities to cope with the circumstances in their lives. The TOL drawings depicted 67 instances where attributes coded as values were mentioned. Altruism and cooperation, autonomy and independence, education valued and promoted, hard work, and religion were all categories of answers given for the prompt asking the participants to identify the fruit in their lives that they could add to the tree (see Appendix for full TOL instructions). The fruit represented gifts that were given by family members in the form of lessons or skills that helped them grow into the people they were at that time.

\section{Relationships}

In participants' drawings, references to family and other relationships showed up repeatedly (169 instances). Codes for this theme included: at least one close relationship with an adult, basic needs met, family, friendly/has positive relationships, and emotional support. Three of the codes pertained to specific relationships in the participants' lives. Family was most frequently 


\section{Examining Resiliency Through Tree of Life}

mentioned (72 instances) and included both foster families and biological parents, siblings, and cousins. Other sources of support came from friends and non-family adults, such as teachers, coaches, and case workers. The other three codes indicated what these relationships provided for the participants. Some participants identified basic needs, such as clothing, shelter, and money being met, whereas other participants focused on emotional needs (e.g., love, care) being met.

\section{Discussion}

The research team identified three main categories of strengths and resources: self-efficacy, values, and relationships. Most of the codes that emerged within these categories align with both the developmental assets framework (Sesma, et al., 2005) and the profile of the resilient adolescent (Henderson \& Millstein, 2003), as well as support a systems view (Masten, 2014b) of working with adolescent refugees.

The most frequently noted resources among participants were their relationships with others, especially their relationships with families. In the developmental assets framework, family is a key external asset in the broader category of supports, along with other adult relationships, caring neighborhoods, and caring school climate (Sesma et al., 2005). Whereas some participants noted adults outside of family as sources of support, especially teachers, coaches, and their caseworkers, the participants in this study noticeably did not include more informal relationships in their neighborhoods as sources of support. As noted in Capps et al. (2015), language and cultural barriers often keep refugees on the outskirts of society. The participants in this study appeared to reflect these challenges in their drawings; although they had some of the external supports that are helpful for all adolescents, their refugee status may create challenges in terms of the types of neighborhood support that might fully round out their experience of external supports.

Within the broader self-efficacy category, the research team identified several instances where participants noted their unique talents, many of which were in the domain of sports or participation in the performing arts. The presence of self-identified talents points again to the importance of schools and communities in providing adolescents with ways to constructively use their time; this is an external asset in the developmental assets framework (Sesma, et al., 2005). For adolescent refugees, opportunities to participate in sports and in arts programs may be of particular importance as a mechanism for resilience, because these are often ways in which adolescents can more broadly connect with their communities. 
Other strengths and resources identified in participants' drawings may be classified as internal assets in the developmental assets framework. Codes related to self-efficacy were the second most frequent codes to occur in the drawings. The developmental assets framework classifies internal assets across four categories: commitment to learning, positive values, social competencies, and positive identity (Sesma et al., 2005). The most frequently noted code within the self-efficacy category was future orientation, which is also included in the positive identity category of the developmental assets framework. The frequency at which participants identified a future orientation for themselves is impressive given that the circumstances of many refugees could create a stronger orientation to survival in the present. The fact that a number of participants held a positive view of their futures, in spite of recent and current challenges, is certainly a mechanism of resiliency (Henderson \& Millstein, 2003), and it also supports the authors' contention that it may be helpful to think about the ways in which these adolescents are capable of moving beyond positive adaptation and to the goal of thriving that is articulated within the PYD framework (Lerner et al., 2003). Although it makes a lot of sense to target immediate needs when working with adolescent refugee clients, especially in the earliest days and weeks of transition into a new living environment, practitioners working with adolescents may also want to consider the ways in which they can help adolescent refugees develop or strengthen a positive orientation to the future as both a mechanism for resilience and a step on the path towards thriving.

Similarly, within the broader values category of the present study, the research team most frequently identified education valued and promoted in the participants' drawings. Again, this aligns with a category of internal assets from the developmental assets framework: commitment to learning (Sesma, et al., 2005). Like the presence of future orientation in the participants' drawing, participants' identification of the importance of education in their lives also serves as a reminder to those who work with adolescent refugees to consider more than their basic needs. Basic needs must be met, and, at the same time, these participants offer insight into their own needs to continue to develop at a higher level. Practitioners working with adolescent refugees may be able to offer support to their clients by helping them navigate the path to furthering their education in a new country and living environment.

\section{Implications for Practitioners}

The findings of this study suggest that the use of a creative arts activity-the TOL-facilitated the identification of several strengths and resources by adolescent refugees. Additionally, these 


\section{Examining Resiliency Through Tree of Life}

strengths and resources were then visually displayed for the participants in a way that showed how they were systemically related to each other. Practitioners working with this population may want to consider the ways in which the TOL may help adolescent refugees consider their own strengths and resources in relation to many aspects of their lives and stories. If resilience science and PYD are both systems approaches (Masten, 2014b), then the TOL offers a way to help adolescent refugees see the multiple components of the systems of which they are a part. Additionally, in line with PYD and more contemporary approaches to fostering the mechanisms of resilience, the use of the TOL allowed participants to focus on what is going well in their lives, rather than past adversity. Whether practitioners use the TOL or some other activity to facilitate conversation, one implication of this study is that adolescent refugees who are invited

to focus on their strengths and resources will discover them. Not a single participant was unable to name a strength or resource in his or her life. The use of art may act as a way for adolescent refugees to express themselves in spite of language barriers (Davis, 2010); the art, rather than words, is a form of language with which they may feel more comfortable. Overall, practitioners may want to use approaches that combine visual creativity with a focus on strengths and resources as a way to help adolescent refugees overcome adversity and thrive.

\section{Study Limitations}

The findings of this study should be considered in light of three key limitations. First, for several participants, while solidly on the path to conversational English, language barriers were present as evidenced by struggles with vocabulary and written language skills. The research team included a Spanish-speaking member who provided language support for Spanish-speaking participants, but participants whose first language was something other than English or Spanish did not receive this sort of support. The TOL activity, while a drawing, also required participants to write several words, and there is a possibility that the richness of some data were lost as a result of participants not having the language skills to write what they wanted to communicate. As a result, there were fewer opportunities to include participant quotes in the analysis, as is commonly found in qualitative research. Although the creative modality served to break down communication barriers to some degree, the TOL activity should be conducted with strong language support in the client's first language when possible.

This study is also limited in its transferability by the wide range of participant ages within the adolescent years. Future work in this area should target more participants to provide greater delineation of strengths and resources at the different stages within adolescence (e.g., early, middle, late). Finally, the overall time that the research team spent with participants was low 
and may not have been adequate for building the type of relational trust that would facilitate rich and complete responses to the TOL prompts. Especially if future work were to investigate the use of the TOL as an intervention with the adolescent refugee population, greater time to build trusting relationships would need to be allocated.

\section{Conclusion}

This report of a study of self-identified strengths and resources among adolescent refugees in northeast Texas through the use of the TOL activity showed that adolescent refugees identify for themselves many of the same strengths and resources as adolescents who are not refugees. Practitioners who help adolescents to leverage these assets are well-situated to foster resiliency and thriving among this population of young people. Creative activities, such as the TOL, may facilitate the discovery of strengths and resources in adolescent refugees, by which they may progress beyond survival of adversity to resiliency and thriving.

\section{References}

American Academy of Pediatrics. (2017). Age limit of pediatrics. Retrieved from http://pediatrics.aappublications.org/content/early/2017/08/17/peds.2017-2151

Bandura, A. (1977). Self-efficacy: Toward a unifying theory of behavioral change. Psychological Review, 84(2), 191-215. doi:10.1037/0033-295X.84.2.191

Bean, T., Derluyn, I., Eurelings-Bontekoe, E., Broekaert, E., \& Spinhoven, P. (2007). Comparing psychological distress, traumatic stress reactions, and experiences of unaccompanied refugee minors with experiences of adolescents accompanied by parents. The Journal of Nervous and Mental Disease, 195(4), 288-297. doi:10.1097/01.nmd.0000243751.49499.93

Berger, P. L., \& Luckmann, T. (2007). The social construction of reality [1966]. In C. Calhoun, J. Gerteis, J. Moody, S. Pfaff, \& I. Virk (Eds.), Contemporary Sociological Theory (2 $2^{\text {nd }}$ ed., pp. 43-51). Malden, MA: Blackwell.

Blakemore, S-J. \& Mills, K. L. (2014). Is adolescence a sensitive period for sociocultural processing? Annual Review of Psychology, 65, 187-207. doi:10.1146/annurev-psych-010213-115202

Capps, R., Newland, K., Fratzke, S., Groves, S., Auclair, G., Fix, M., \& McHugh, M. (2015). Integrating refugees in the United States: The successes and challenges of resettlement in a global context. Statistical Journal of the IAOS, 31(3), 341-367. doi:10.3233/SJI-150918

Collier, L. (2015). Helping immigrant children heal. American Psychological Association, 46(3), 58. Retrieved from: http://www.apa.org/monit or/2015/03/immigrant-children.aspx 
Journal of Youth Development | http://jyd.pitt.edu/ | Vol. 14 Issue 2 DOI 10.5195/jyd.2019.692

Examining Resiliency Through Tree of Life

Davis, B. (2010). Hermeneutic methods in art therapy research with international students. Arts in Psychotherapy, 37(3), 179-189. doi:10.1016/j.aip.2010.03.003

Denborough, D. (2008). Responding to vulnerable children. In D. Denborough (Ed.), Collective narrative practice: Responding to individuals, groups, and communities who have experienced trauma (pp. 71-98). Adelaide, Australia: Dulwich Centre.

Dominguez Villegas, R. (2014, September). Central Americans and "la bestia": The route, dangers, and government responses. Migration Information Source, the online journal of Migration Policy Institute. Retrieved from https://www.migrationpolicy.org/article/central-american-migrants-and\%E2\%80\%9Cla-bestia\%E2\%80\%9D-route-dangers-and-government-responses

Dulwich Centre. (n.d.). Dulwich Centre: Our story. Retrieved from https://dulwichcentre.com.au/aboutdulwich-centre/

Fergus, S. \& Zimmerman, M. A. (2005). Adolescent resilience: A framework for understanding healthy development in the face of risk. Annual Review of Public Health, 26, 399-419. doi:10.1146/annurev.publhealth.26.021304.144357

Figures at a glance. (n.d.). Retrieved from http://www.unhcr.org/en-us/figures-at-a-glance.html

Franco, D. (2018). Trauma without borders: The necessity for school-based interventions in treating unaccompanied refugee minors. Child and Adolescent Social Work Journal, 35, 551-565. doi:10.1007/s10560-018-0552-6

Greene, R. R. (2010). Holocaust survivors: Resilience revisited. Journal of Human Behavior in the Social Environment, 20, 411-422.

Harter, S. (1990). Developmental differences in the nature of self-representations: Implications for the understanding, assessment, and treatment of maladaptive behavior. Cognitive Therapy and Research, 14(2), 113-142. doi:10.1007/BF01176205

Henderson, N., \& Millstein, M. M. (2003). Resiliency in schools. Thousand Oaks, CA: Corwin Press, Inc. Huemer, J., Karnik, N. S. Voelkl-Kernstock, S., Granditsch, E., Dervic, K., Friedrich, M. H., \& Steiner, H. (2009). Mental health issues in unaccompanied refugee minors. Child and Adolescent Psychiatry and Mental Health, 3(13), 1-10. doi:10.1186/1753-2000-3-13

Hughes, G. (2013). Finding a voice through 'The Tree of Life': A strength-based approach to mental health for refugee children and families in schools. Clinical Child Psychology and Psychiatry 19(1) 139-153. doi: $10.1177 / 1359104513476719$

Keles, S., Friborg, O, Idsöe, T., Sirin, S., \& Oppedal, B. (2018). Resilience and acculturation among unaccompanied refugee minors. International Journal of Behavioral Development, 42, 52-63. doi:10.1177/0165025416658136

Kroger, J., Martinussen, M., \& Marcia, J. E. (2010). Identity status change during adolescence and young adulthood: A meta-analysis. Journal of Adolescence, 33(5), 683-698. doi:10.1016/j.adolescence.2009.11.002 
Journal of Youth Development | http://jyd.pitt.edu/ | Vol. 14 Issue 2 DOI 10.5195/jyd.2019.692

Examining Resiliency Through Tree of Life

Leech, N. L., \& Onwuegbuzie, A. J. (2007). An array of qualitative data analysis tools: A call for data analysis triangulation. School Psychology Quarterly, 22, 557-584. doi:10.1037/10453830.22.4.557

Lerner, R. M., Dowling, E. M., Anderson, P. M. (2003). Positive youth development: Thriving as the basis of personhood and civil society. Applied Developmental Science, 7(3), 172-180. doi:10.1207/S1532480XADS0703_8

Masten, A. S. (2014a). Global perspectives on resilience in children and youth, Child Development, 85(1), 6-20. doi:10.1111/cdev.12205

Masten, A. S. (2014b). Invited commentary: Resilience and positive youth development frameworks in developmental science. Journal of Youth and Adolescence, 43(6), 1018-1024. doi:10.1007/s10964-014-0118-7

Masten, A. S. \& Cicchetti, D. (2010). Developmental cascades. Development and Psychopathology, 22(3), 491-495. doi:10.1017/S0954579410000222

Méndez, G. A., \& Cole, E. M. (2014). Engaging Latino families in therapy: Application of the Tree of Life technique. Journal of Family Psychotherapy, 25(3), 209-224. doi:10.1080/08975353.2014.939932

Miles, M. B., Huberman, A. M., \& Saldaña, J. (2013). Qualitative data analysis: A methods sourcebook. Thousand Oaks, CA: Sage.

Muhr, T. (2009). ATLAS.ti (Version 6.0) [Computer software]. Berlin, Germany: Scientific Software Development.

Ncube, N. (2006). The tree of life project. International Journal of Narrative Therapy \& Community Work, 2006(1), 3-16. Retrieved from http://search.informit.com.au.ezproxy.tcu.edu/documentSummary;dn=197106237773394;res=IE LHEA

Patton, M. Q. (2014). Qualitative research and evaluation methods ( $4^{\text {th }}$ ed.). Thousand Oaks, CA: Sage.

Remley, T. P., \& Herlihy, B. (2016). Ethical, legal, and professional issues in counseling (5 ${ }^{\text {th }}$ ed.). Boston, MA: Pearson.

Rutter, M. (2012). Resilience as a dynamic concept. Development and Psychopathology, 24, 335-344. doi:10.1017/S0954579412000028

Scales, P. C., Benson, P. L., \& Leffert, N. (2000). Contribution of developmental assets to the prediction of thriving among adolescents. Applied Developmental Science, 4(1), 27-46. doi: 10.1207/S1532480XADS0401_3

Sebastian, C., Burnett, S., \& Blakemore, S-J. (2008). Development of the self-concept during adolescence. Trends in Cognitive Sciences, 12(11), 441-446. doi:10.1016/j.tics.2008.07.008

Sesma, A., Mannes, M. \& Scales, P. C. (2005). Positive adaptation, resilience, and the developmental asset framework. In S. Goldstein \& R. B. Brooks (Eds.), Handbook of resilience in children (pp. 281-296). New York, NY: Kluwer Academic/Plenum. 
Journal of Youth Development | http://jyd.pitt.edu/ | Vol. 14 Issue 2 DOI 10.5195/jyd.2019.692

Examining Resiliency Through Tree of Life

Stake, R. E. (2005). Qualitative case studies. In N. K. Denzin \& Y. S. Lincoln (Eds.), The Sage handbook of qualitative research ( $2^{\text {nd }}$ ed., pp. 443-466). Thousand Oaks, CA: Sage.

Strauss, A., \& Corbin, J. (1990). Basics of qualitative research: Grounded theory procedures and techniques. Newbury Park, CA: SAGE.

Tshabangu-Soko, T. S., \& Caron, R. M. (2011). English for speakers of other languages (ESOL): Improving English language acquisition for preliterate and nonliterate adult African refugees. Journal of Immigrant \& Refugee Studies, 9(4), 416-433. doi:10.1080/15562948.2011.616812

Werner, E. (2005). Resilience and recovery: Findings from the Kauai longitudinal study. Research Policy, and Practice in Children's Mental Health, 19, 11-14.

What is a refugee? Definition and meaning. (n.d.). Retrieved from http://www.unrefugees.org/what-is-arefugee/

Wheeldon, J. (2010). Mapping mixed methods research: Methods, measures, and meaning. Journal of Mixed Methods Research, 4(2), 87-102. doi:10.1177/1558689809358755 


\section{Appendix}

\section{"Tree of Life" Script}

Tell me what you know about trees. (Paraphrase and validate all answers.) (Summarize all answers and add any missing information: tall, short, big, small, young, old, roots, shared roots, trunk, branches, the ground, green or different colors, leaves, fruit, water, sunlight, threats such as people or storms or fire or disease, etc.)

For the rest of the hour we will each be drawing our own tree, in a very special way. You will have one piece of paper and can use all of these colored pencils. We will start by drawing a tree, any tree that you wish. Just make sure it has all the parts that we just talked about: roots, trunk, branches, leaves, and fruit. You can add any extras that you would like. It is important to draw each of these pieces of the tree because each part will represent something in your life and later we will be writing on each part. Compost heaps are often used to produce fertilizer for trees and plants. To represent your compost heap, draw a pile or container to the side of your drawing. Write down anything in your compost heap that is part of your background, but which you no longer want to define you. These can be places, people, problems, or experiences.

Let's begin. Draw your tree.

Let's think about what the roots mean. You will write words or draw pictures that represent where you come from. Your roots. Think about the country you come from. The town, city, or village. What language did you first know? What culture do you come from? Is there a family name or ancestry that you can think of? What about who has taught you the most in life? You're most favorite place? Is there a favorite song or dance that you love?

Now, let's think about the ground means. You can write words or draw pictures that represent your life right now. Where do you live right now? How do you spend your day? School? Games? Friends? If I were to spend a day with you, what would be doing? What do you enjoy doing?

You can go back to add to any part of your tree. You will probably get more ideas as we go on.

Now, let's think about what the trunk means. You can write words or draw pictures that represent your special talents. What are you good at? What skills do you have? What do the people in your life praise you for? I wonder who taught you those skills? Maybe you can 
Examining Resiliency Through Tree of Life

remember how you first learned or practiced these skills. If a memory or a person comes to mind, go ahead and add them too.

Now, let's think about the branches. You can write words or draw pictures that represent your hopes and dreams. What goals do you have for your life? What special wishes do you want to happen in your life? Do you have any of the same dreams as your family or friends? I wonder when these dreams first started? Who supports these dreams? Did someone give you the idea to have this dream? It can be hard to hold onto hopes and dreams. How do you keep holding onto your special hopes?

Remember, you can go back to add to any part of your tree. You will probably get more ideas as we go on.

Now, let's think about what the leaves mean. You can write names or draw pictures of the people who are important to you. You might first think about your family and friends. Past or present. Living or not living. You can use heroes from a movie or book. A famous person that you admire. What about a beloved pet or imaginary friend? While thinking about these important names, write down any special memories that come to mind. If you think about a special moment with someone, just write that down next to their leaf.

Now, let's think about the fruit on your tree and what these mean. You can write or draw pictures that represent the gifts that have been given to you in life. These don't have to be material gifts. What about kindness that has been given to you? Or love or care or help? It might be helpful to look at your roots or leaves and see if any special characteristics or traits have been passed on to you. Did you learn patience from someone in your family? That's a gift they gave you. People give gifts for a reason. I wonder what the givers in your life appreciate about you that makes them want to give you gifts.

Now, I wonder if your fruit could leave behind some seeds. Draw some seeds from your fruit. Let's think about what these seeds could mean. You can write or draw pictures that represent the legacies you wish to leave behind. What impact do you want to leave on others? How do you wish to change the world? These might be similar or different to the fruit on your tree.

Now, take your tree of your life and let's make a forest of life by taping them together up on this wall. (Provide tape, but don't direct the placement of trees.) Look at these beautiful trees. They make a strong and vibrant forest together! Take a few minutes to look at each other's 
Examining Resiliency Through Tree of Life

trees. Let us honor each other's trees of life by choosing one or more trees that are different from your own and writing some words of encouragement, appreciation, or support.

This is a strong forest of trees and each tree is different but somehow connected to the other trees. Let's think about some of those threats to forests and trees we mentioned earlier. Let's think about what the storms mean. You can write or draw a picture of a storm that represents a problem or threat in your life. Take your picture back so you can draw on it again.

(Say this part while they are drawing the storms.) Are trees vulnerable to these storms? Yes. Is it correct to say that just like trees, children are sometimes vulnerable to life storms? Yes. But just like trees, children are not at fault for the storms in their life. And just like children, trees are strong and can make it through storms. Now, write or draw a picture that represents how you have successfully responded to a storm in your life. Put this near the storm you drew on your paper. You might use things that are already on your tree for this part or maybe you'll think of a new way you want handle storms in life. 